\title{
A model based on DOC data for determination of alum dosing for drinking water treatment
}

\author{
$\underline{\text { H. Daraei }}^{\text {a,e }}{ }^{\text {, J. Awad }}{ }^{\text {a,d }}$, E. Bertone ${ }^{\text {b }}$, R.A. Stewart ${ }^{\text {b }}$, C.W.K. Chow ${ }^{\text {a }}$, J. Duan ${ }^{\text {a,c }}$ and J. van Leeuwen ${ }^{\text {a,c }}$ \\ ${ }^{a}$ Scarce Resources and Circular Economy (ScaRCE), UniSA STEM, University of South Australia, Adelaide, \\ SA, Australia, ${ }^{b}$ Griffith University, Gold Coast, QLD, Australia, ${ }^{c}$ Future Industries Institute, Adelaide, SA, \\ Australia, ${ }^{d}$ CSIRO Land \& Water, Adelaide, SA, Australia, ${ }^{e}$ Environmental Health Research Center, \\ Kurdistan University of Medical Sciences, Sanandaj, Kurdistan, Iran; \\ Email: Hiua.Daraei@mymail.UniSA.edu.Au
}

\begin{abstract}
In this paper, the development of a model is described which is designed for the determination of alum dosing needed for controlled removal of dissolved organic carbon (DOC) in drinking water treatment. Development of the model is intended to be applied for feed-forward prediction of required alum dosing, using raw water DOC data along with turbidity data.
\end{abstract}

To develop the DOC-based model, 72 samples were collected from 16 different surface water sources. Seventeen samples (from 15 different sources) were used for jar tests and model development. The remaining samples from the same water sources were used for testing the model performance in a comparison study with a previously established model. That model, named mEnCo is based on other parameters, i.e., ' colour and UV light absorbance at $254 \mathrm{~nm}\left(\mathrm{~A}_{254}\right)$, and with turbidity data.

For the new model development, data of DOC, $\mathrm{A}_{254}$, colour and turbidity were acquired for the raw water samples and following treatment with alum in jar tests. These data were then analysed for changes in DOC removal rates with increasing alum dosing. From an understanding of the DOC removals behaving as an 'exponential decay' and the distinction between the coagulable and non-coagulable (recalcitrant) portions of the DOC pool, a hybrid model based on the removal mechanism of DOC is proposed here. An exponential decay function was found to be suitable for the fitting of data of residual DOC following treatment with an increase in alum dose. The average $\mathrm{R}^{2}$ (adjusted) value for the model fitted to the jar test data of the samples studied is $0.96 \pm 0.05$.

A dose set at a target of $85.1 \%$ coagulable DOC removal was found to equate to an 'enhanced' dose (EnD), where DOC removal in treated drinking water is practically optimized. This value was obtained from the average of the 17 waters studied using the jar test procedure. Determinations using the model were compared to the EnD obtained experimentally through jar testing and the EnD values obtained through the mEnCo software. The results show a comparable (and slightly improved) performance to the original mEnCo software for the newly developed DOC-based model, based on the EnD data acquired through jar testing. The new DOC model also shows potential suitable capability for prediction of the EnD for waters with very high organic matter content as may occur under extreme climate conditions. These particular samples ( 5 out of 17 samples jar tested) were out of the designed operational limits of the mEnCo model (i.e., $14 \mathrm{mg} \mathrm{L}^{-1} \mathrm{DOC}, 0.55 \mathrm{~cm}^{-1}$ absorbance) and were not included for comparison. A comparative study between the new DOC model and mEnCo using 33 out of 55 testing samples which were in the operational range of the mEnCo model demonstrated the comparative predictivity for these two models, which use different input data $\left(\mathrm{R}^{2}=0.92\right)$.

A software referred to as 'WTC-DOC_Coag' was developed using the new DOC-based model with intent as an extended option to the previously established WTC-Coag software. It is proposed that the DOC-based model, with the capability to provide a comparable performance for dose prediction using input signal from an online DOC analyser, has the potential for online feedforward coagulant control. This might also be in combination with other model systems which use different input signals, then increasing the overall robustness of the control system. Validation of the WTC-DOC_Coag performance for suitability at drinking water plants is required and planning for this is to include domestic and overseas plants.

Keywords: Drinking water treatment, coagulation-flocculation process, dissolved organic carbon (DOC) based model, coagulant dosing control, Online control 


\section{INTRODUCTION}

Surface waters used as drinking water sources, often need to be treated to meet required guidelines and/or regulatory standards for safety, quality and meeting consumer's acceptability (Van Leeuwen et al., 2003). Producing potable water that is safe, clear, colourless, and without unpleasant taste or smell is the mission of the water industry globally, and generally requires raw surface waters to be treated at drinking water treatment plants (DWTPs) (Szlyk et al., 1989). Coagulation-flocculation using metal coagulants (e.g. alum) followed by sedimentation and filtration is a commonly used treatment procedure to remove natural colour, turbidity and organic compounds from surface waters (Van Leeuwen et al., 2003) and is referred to as conventional water treatment. However, this type of treatment has been identified to have only partial effectiveness in removing organic matter (Xie et al., 2012). As a consequence, residual organic matter present in water after the coagulation-flocculation stage can act as a precursor for disinfection by-product (DBPs) formation during the disinfection stage, and this can be a serious health concern (Knight et al., 2010). Hence, maximizing organic matter removal is usually a key consideration in DWTP operations (Van Leeuwen et al., 2003).

Several factors including temperature, $\mathrm{pH} /$ alkalinity, coagulant type and dose impact organic matter (measured as DOC) removal by the coagulation-flocculation process (Pernitsky and Edzwald, 2006). For various metal coagulants, their optimum coagulation $\mathrm{pH}$ has been identified and reported with respect to DOC removal efficiency (Van Leeuwen et al., 2003; Xie et al., 2012). At a given $\mathrm{pH}$, the DOC removal rate $\left(\frac{\Delta(D O C)}{\Delta(\text { coagulant dose })}\right)$ decreases with increasing coagulant dose (Van Leeuwen et al., 2003). Even at a very high metal coagulant dose, there remains a $\mathrm{pH}$-dependent portion of DOC which is not removed. Hence, natural organic matter present in surface waters can be categorized into coagulable and recalcitrant (or non-coagulable) fractions (Kastl et al., 2004). Regulatory standards of DBPs present in drinking waters in the UK, Europe and Australia are set based on concentrations of particular groups of DBPs in the supply water. In the USA, in order to meet regulatory standards regarding DBPs in treated water supplies, DWTPs are required to achieve specified total organic carbon (TOC) removal targets, based on influent total organic carbon concentration and water alkalinity. This specific coagulation-based treatment of water to practically maximize removal of organics is referred to by the water industry as 'enhanced coagulation'.

Determining the coagulant dose needed to comply with guideline/regulatory standards including organic matter removal and/or DBPs content limits in supply water is a daily task for DWTPs control operators. This task is more challenging under conditions with fluctuating influent water quality and extreme climate conditions that can significantly impact the influent water quality. Development of prediction models or decision support systems for optimum coagulant dose prediction has been described previously to assist DWTPs operators in maximising DOC removal and maintain DBP formation below standard thresholds. Identifying and modelling the behaviour of DOC removal by coagulant dose addition is the first stage of developing such system controls. Previous developments have often been based on data-driven empirical models, using influent water quality data such as colour, $\mathrm{A}_{254}$ and turbidity (Ellis et al., 1991; Kennedy et al., 2015; Van Leeuwen et al., 1999). There are also research studies reported on coagulant dose optimisation through organic matter removal assessment and maximisation (Kastl et al., 2004; Van Leeuwen et al., 2005; Zhao et al., 2019). However, the application of these models in an online control system can be technically very challenging due to online signal (e.g., $\mathrm{A}_{254}$, colour, or fluorescence) interferences (then requiring water pre-treatment), probe reliability and fouling, extreme climate conditions having major effects on water quality, and operational limits of established prediction models.

Here we describe a new coagulant prediction model, based on raw water DOC as an input signal, that was developed for potential application in an online control system. The model was developed, and laboratory tested using a wide range of surface water samples collected throughout Australia.

\section{MATERIALS AND METHODS}

\subsection{Water Sampling}

To develop the DOC based model, 72 samples were collected from 16 different surface water sources $(1 \mathrm{x}$ Australian Capital Territory (ACT), 4 x Queensland (QLD), 9 x South Australia (SA) and $2 \times$ Victoria (VIC). The 16 water sources were coded P01 to P16. Seventeen samples (from 15 different sources) were then used for jar tests (a simulation test of conventional drinking water treatment) and model development. The remaining samples [from the same water sources (except Summit Storage, SA) of ACT, QLD, and SA] were used for testing the model performance for prediction. Water samples were collected between November 2018 and February 2021 and were stored at $\sim 4^{\circ} \mathrm{C}$ before jar testing and water quality analyses. 


\subsection{Water quality data collection}

The DOC concentrations of water samples were determined using an organic carbon analyser (Model 820, Sievers Instruments Inc., USA). Absorbance at $254 \mathrm{~nm}\left(\mathrm{~A}_{254}\right)$ was measured using a UV/VIS spectrophotometer (Model UV-120, Miostech, Australia) equipped with a $1 \mathrm{~cm}$ quartz cuvette. Colour, in Hazen units (HU), was determined by the spectrophotometric technique described in van Leeuwen et al. (2005). Samples were filtered through $0.45 \mu \mathrm{m}$ polyether sulfone membrane filters for true colour, $\mathrm{A}_{254}$ and DOC analyses. Turbidity was measured in the nephelometric unit (NTU) using a Hach turbidimeter (Model 2100 AN, USA).

\subsection{Jar tests}

In order to simulate the conventional water treatment process at laboratory scale, jar tests were conducted on representative samples with diverse water qualities, as previously described by van Leeuwen et al. (1999). A $28 \%$ alum $\left[\mathrm{Al}_{2}\left(\mathrm{SO}_{4}\right)_{3} .18 \mathrm{H}_{2} 0\right]$ solution (IXOM Operations Pty Ltd, Australia) was used to prepare $2000 \mathrm{mg} \mathrm{L}^{-}$ ${ }^{1}$ (as Al) stock solutions. All jar tests were performed under the $\mathrm{pH}$-controlled condition, at $\mathrm{pH} 6.1 \pm 0.1$. $\mathrm{HCl}$ $0.2 \mathrm{~N}$ and $\mathrm{NaOH} 0.2 \mathrm{~N}$ solutions were used for $\mathrm{pH}$ adjustment during jar test experiments. Raw water $\mathrm{A}_{254}$, colour, and turbidity data were used to estimate the alum doses needed in jar tests to include near-maximum removal of coagulable DOC. The alum doses for the six jars in each experiment were determined through enhanced coagulant dose $\mathrm{EnD}$ prediction using mEnCo software $\left(\mathrm{EnD}_{\mathrm{mEnCo}, \mathrm{p}}\right)$, (i.e., $25 \%, 50 \%, 75 \%, 100 \%$, $150 \%$, and $250 \%$ of $\left.\mathrm{EnD}_{\mathrm{mEnCo}, \mathrm{p}}\right)$.

\subsection{Model and software development}

Each jar test provided seven DOC data points (from six jars plus raw water data) and these were fitted to selected algorithms generated using Table Curve $C$ software 2D Windows v4.00 (Hearne Software Pty Ltd, Melbourne, Victoria). The first derivative analysis of the fitted model to the jar test data was performed using Table Curve software. The developed model was then incorporated into a previously developed software entitled WTC-Coag which is a Microsoft Office Excel interface-based version of mEnCo software used for alum coagulant dose prediction.

\section{RESULTS AND DISCUSSION}

\subsection{Modelling of the jar tests data}

Water quality data including DOC, $\mathrm{A}_{254}$, colour, and turbidity were collected for 17 samples before and following jar testing using six selected alum doses, as described. The DOC removal results are in agreement with the previously described behaviour of decreasing efficiency with increasing coagulant dose (Figure 1).

The recalcitrant or non-coagulable DOC portion is evident in the studied samples particularly at excess alum dose $\left(250 \%\right.$ of $\left.\mathrm{EnD}_{\mathrm{mEnCo}, \mathrm{p}}\right)$ (Figure 1$)$, which has been described previously (Kastl et al., 2004; Van Leeuwen et al., 2005). The exponential decay function (Equation 1) was then used for the fitting of the jar test DOC data with increasing alum dose (i.e., residual DOC (res_DOC) versus alum dose). An example of jar test data fitting to

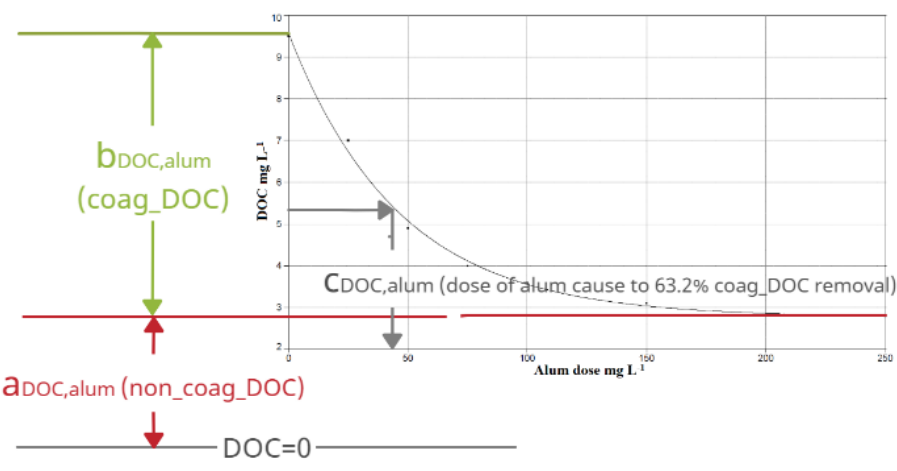

Figure 1. The exponential decay function (Equation 1) fitting to the jar test data of Myponga River sample (P10_01); $\left(a_{D O C, \text { alum }}=\right.$ $2.8 \mathrm{mg} \mathrm{L}^{-1} \mathrm{DOC} ; b_{D O C, \text { alum }}=6.8 \mathrm{mg} \mathrm{L}^{-1} \mathrm{DOC} ; c_{D O C, \text { alum }}=46.2$ $\mathrm{mg} \mathrm{L}^{-1}$ Alum; Adjusted $\mathrm{R}^{2}=0.99$. Equation 1 is shown in Figure 1. The results of the 17 model fittings to the jar test data are presented in Table 1.

$$
\text { res_DOC }=a_{D O C, \text { alum }}+b_{D O C, \text { alum }} e^{\left(-\frac{\text { alum }}{c_{D O C, \text { alum }}}\right)}
$$


where res_DOC is the residual DOC after treatment, alum is the applied alum dose, $a_{D O C, \text { alum }}, b_{D O C, \text { alum }}$, and $c_{D O C, \text { alum }}$ are the equation constants, specific for each water.

As indicated in the following equations, the $a_{D O C, \text { alum }}$ constant is equivalent to the res_DOC at excess alum dose condition $\left(\right.$ alum $=$ alum $\left._{\infty}=\infty \mathrm{mg} \mathrm{L}^{-1}\right)$ which can be named as res_DOC alum $_{\infty}$ or non-coagulable DOC (non_coag_DOC).

$$
r e S_{-} D O C=a_{D O C, \text { alum }}+b_{D O C, \text { alum }} e^{\left(-\frac{\text { alum }_{\infty}}{c_{D O C, \text { alum }}}\right)} \quad \Rightarrow r e s_{-} D O C_{\text {alum }}=a_{D O C, \text { alum }}
$$

The " $b_{D O C, \text { alum }}$ " constant is equivalent to the coagulable DOC (coag_DOC) which can be derived from Equation 1 where no alum dose applied $\left(\right.$ alum $=$ alum $\left._{z}=0 \mathrm{mg} \mathrm{L}^{-1}\right)$ which means res_DOC is equal to the initial DOC (DOC $i)$ in the raw water.

$$
\begin{aligned}
& r e S_{-} D O C=a_{D O C, \text { alum }}+b_{D O C, \text { alum }} e^{\left(-\frac{\text { alum }_{Z}}{c_{D O C, \text { alum }}}\right)} \quad \Rightarrow \quad(\text { res_DOC }=\text { DOCi }) \\
& =>\quad b_{D O C, \text { alum }}=r e s_{-} D O C-a_{D O C, \text { alum }} \quad \Rightarrow \quad b_{D O C, \text { alum }}=\text { DOCi }- \text { non_coag_DOC } \\
& \Rightarrow \quad b_{D O C, \text { alum }}=\text { COag_DOC }_{-}
\end{aligned}
$$

The " $C_{D O C \text {,alum }}$ " constant is equivalent to a coagulant dose which can theoretically lead to $63.2 \%$ coag_DOC removal, where alum dose is equal to $c_{D O C, \text { alum }}\left(\right.$ alum $=$ alum $_{c}=c_{D O C, \text { alum }} \mathrm{mg} \mathrm{L}^{-1}$ alum$)$ as shown in the following.

$$
\begin{aligned}
& r e S_{-} D O C=a_{D O C, \text { alum }}+b_{D O C, \text { alum }} e^{\left(-\frac{\text { alum }_{C}}{c_{D O C, \text { alum }}}\right)} \quad \Rightarrow \quad r e S_{-} D O M=a_{\mathrm{DOM}, \text { alum }}+b_{\mathrm{DOM}, \text { alum }} e^{(-1)}
\end{aligned}
$$

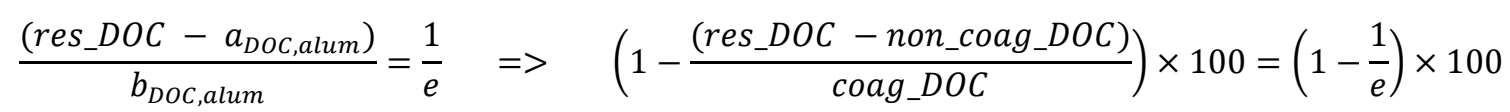

$$
\begin{aligned}
& =>\left(1-\frac{{\text { res } \text { Coag }_{-D O C}}_{\text {coag_DOC }}}{\text { con }_{-}} \times 100=\% \text { coag_DOC_Removal }=63.2 \%\right.
\end{aligned}
$$

\begin{tabular}{|c|c|c|c|c|c|c|c|c|}
\hline \multicolumn{3}{|c|}{ Sample's information } & \multicolumn{2}{|c|}{ Organic matter coagulability } & \multicolumn{4}{|c|}{ Model fitting outputs } \\
\hline Sample & $\begin{array}{c}\text { DOC } \\
\mathrm{mg} \mathrm{L}^{-1}\end{array}$ & $\begin{array}{c}\text { Tb }^{1} \\
\text { NTU } \\
\end{array}$ & \%coag_DOC ${ }^{2}$ & $\% \operatorname{coag} \_D O C \_R^{3}$ & $\begin{array}{c}a_{D O C, \text { alum }} \\
\mathrm{mg} \mathrm{L}^{-1}\end{array}$ & $\begin{array}{c}\boldsymbol{b}_{\text {Doc,alum }} \\
\mathrm{mg} \mathrm{L}^{-1}\end{array}$ & $\begin{array}{c}c_{D O C, \text { alum }} \\
\mathrm{mg} \mathrm{L}^{-1}\end{array}$ & $R^{2}$ \\
\hline P01_01 & 19.5 & 5.4 & 62 & 89 & 7.3 & 12.3 & 90.9 & 0.99 \\
\hline P02_01 & 2.3 & 1.0 & 49 & 83 & 1.2 & 1.2 & 12.6 & 0.82 \\
\hline P03_01 & 8.5 & 0.9 & 49 & 88 & 4.3 & 4.2 & 32.9 & 0.99 \\
\hline P03-02 & 17.9 & 16.1 & 73 & 92 & 5.0 & 13.0 & 65.5 & 1.00 \\
\hline P04_01 & 2.1 & 1.4 & 54 & 84 & 1.1 & 1.0 & 5.8 & 0.96 \\
\hline P05_01 & 15.6 & 0.7 & 90 & 95 & 1.7 & 13.9 & 36.3 & 1.00 \\
\hline P06_01 & 3.7 & 19.2 & 50 & 81 & 1.8 & 2.0 & 24.2 & 0.91 \\
\hline P07_01 & 11.8 & 0.2 & 65 & 93 & 4.2 & 8.0 & 35.8 & 0.94 \\
\hline P08_00 & 4.9 & 118.0 & 46 & 64 & 2.6 & 2.4 & 53.2 & 0.88 \\
\hline P08_01 & 2.9 & 36.0 & 46 & 74 & 1.6 & 1.4 & 23.0 & 0.94 \\
\hline P09_01 & 0.7 & 0.1 & N/A & N/A & 0.6 & 0.1 & 1.0 & $\mathrm{~N} / \mathrm{A}$ \\
\hline P10_01 & 9.5 & 4.3 & 71 & 90 & 2.8 & 6.8 & 46.2 & 0.99 \\
\hline P11_01 & 30.7 & 19.9 & 55 & 89 & 13.9 & 16.9 & 123.8 & 0.98 \\
\hline P12_01 & 3.5 & 5.6 & 37 & 79 & 2.2 & 1.3 & 15.8 & 0.99 \\
\hline P13_01 & 15.6 & 110.9 & 52 & 85 & 7.5 & 8.0 & 82.2 & 0.99 \\
\hline P15_01 & 1.4 & 0.6 & 51 & 86 & 0.7 & 0.7 & 3.6 & 0.95 \\
\hline P16_01 & 3.2 & 3.2 & 68 & 91 & 1.0 & 2.2 & 12.7 & 0.99 \\
\hline Mean & 9.1 & 20.2 & $57.3^{*}$ & $85.1^{*}$ & 3.5 & 5.6 & 39.2 & $0.96^{*}$ \\
\hline StDev & 8.4 & 36.8 & $13.3^{*}$ & $7.9^{*}$ & 3.4 & 5.5 & 34.4 & $0.05^{*}$ \\
\hline
\end{tabular}

The " $C_{D O C \text {,alum }}$ " constant for a specific coagulant like alum can be theoretically dependent on the treatment process parameters such as process $\mathrm{pH}$ and temperature. Graphical descriptions for the model constants are presented in Figure 1.

Table 1. The results of the model fittings to the jar test data for the 17 water samples

${ }^{1}$ Turbidity; ${ }^{2}$ Percentage of coagulable DOC portion; ${ }^{3} \%$ coag_DOC_R at the enhanced coagulant dose $\left(\mathrm{EnD}_{\mathrm{s}}\right)$;

As can be seen from the adjusted $\mathrm{R}^{2}$ values detailed in Table 1 (average $\pm \mathrm{SD}=0.96 \pm 0.05$ ), the exponential decay equation models well the res_DOC versus alum dose data for the 16 out of 17 water samples of this study (Table 1). The Blue Lake (P09-01) sample was excluded from model fitting due to it having very low coag_DOC content. 


\subsection{Model-based feedforward system control}

In order to develop a model for alum dose prediction to achieve a $\%$ target res_DOC, which is based on the exponential decay function, the model constants i.e., $a_{D O C, \text { alum }}, b_{D O C, \text { alum }}$, and $c_{D O C, \text { alum }}$ need to be determined. van Leeuwen et al. (2003) developed three different models to attain these three constants separately(Van Leeuwen et al., 2003). Rearranging equations 1 to 4, as shown in Equation 5, can simplify the model as the $c_{D O C \text {,alum }}$ would be the only required model constant in the rearranged equation to predict the required alum dose to achieve a desirable percentage coagulable DOC removal (\%coag_DOC_R) for any particular water sample.

$$
\% \text { Coag_R }_{-}=\left(1-e^{\left(-\frac{\text { alum }}{c_{\text {DOC }, \text { alum }}}\right)}\right) \times 100 \quad \Rightarrow \quad \text { alum }=-\ln \left(1-\frac{\% \text { Coag_R }_{1}}{100}\right) \times C_{D O C, \text { alum }}
$$

The model-fitting results presented in Table 1 for the 17 samples show the variation of the $c_{D O C \text {, alum }}$ in samples with different DOC contents. The results indicate a direct correlation between DOC in the targeted water sample and the obtained $c_{D O C \text {,alum }}$ value for the same sample through jar test data. This direct correlation is explainable through the presented $c_{D O C \text {,alum }}$ definition; by increasing the DOC, the coag_DOC portion would be increased as well, for surface waters generally. This means that a higher alum dose is needed to remove $63.2 \%$ of coag_DOC content, which is the $c_{D O C}$,alum definition. This leads to the concept of developing a model to predict the $c_{D O C \text {,alum }}$ through the DOC concentration of the targeted water sample similar to the one van Leeuwen et al. (2005) previously performed for $\mathrm{A}_{254}$ and colour-based model through linear regression. To develop this model, the dataset including 17 data points of DOC versus $c_{D O C}$,alum presented in Table 1 were analysed using Table Curve v.4 software. A simple power equation (equation 6) was found to be effective to predict the variation of the $c_{D O C}$,alum by DOC change as indicated in Figure 2.

$$
c_{D O C, \text { alum }, p}=f_{D O C, c} \times D O C^{g_{D O C, c}}
$$

where $c_{D O C, \text { alum, } p}$ is the predicted $c_{D O C, \text { alum }}$, the $\mathrm{f}_{\mathrm{DOC}, \mathrm{c}}$ and $\mathrm{g}_{\mathrm{DOC}, \mathrm{c}}$ are the power equation constants to predict $C_{D O C, \text { alum }}$ using DOC data. The power model fitting to the data is shown in Figure 3 . The $\mathrm{f}_{\text {DOC,c }}$ value $(5.8 \mathrm{mg}$ $\mathrm{L}^{-1}$ alum) is equal to the $c_{D O C, \text { alum }}$ value for a sample with a nominal $1 \mathrm{mg} \mathrm{L}^{-1}$ DOC content and $\mathrm{g}_{\mathrm{DOC}, \mathrm{c}}$ is the power rate of the increase in $c_{D O C}$,alum for each one $\mathrm{mg} \mathrm{L}^{-1}$ increase in the DOC. The value less than 1 (i.e., 0.88 ) for the $\mathrm{g}_{\mathrm{DOC}, \mathrm{c}}$ indicates the decreasing rate of required alum dose per mg DOC removal with an increase in DOC content. The observed deviation between the fitted model and experimental data may be related to variance and/or errors associated with the experimental data. However, since the model does not consider DOC characteristics and is developed only based on DOC concentration, the observed deviation can be due to high diversity regarding organic matter characteristics (e.g., mean \pm SD of DOC specific $\mathrm{A}_{254}\left(\mathrm{SUVA}_{254}\right)$ equal to $3.2 \pm 1.5 \mathrm{~L} \mathrm{~m}^{-1} \mathrm{mg}^{-1}$ ). As our DOC only based model is a simplified model for more practical operational use, a certain degree of uncertainty/error was expected, which nevertheless was relatively small $\left(R^{2}\right.$ (adjusted $\left.)=0.84\right)$.

Using Equation 6 for any sample with known DOC, $c_{D O C, \text { alum }}$ can be determined and from this, the alum dose for any desirable \%coag DOC R can be estimated using Equation 5. For instance, in the case of the Myponga River sample (P10_01) with $9.5 \mathrm{mg} \mathrm{L}^{-1} \mathrm{DOC}$, the calculated $c_{D O C, \text { alum }, p}$ will be $42.1 \mathrm{mg} \mathrm{L}^{-1}$ alum through Equation $6\left(c_{\text {DOC }, \text { alum }, p}=5.8 \times 9.5^{(0.88)}=42.1 \mathrm{mg}\right.$ $\mathrm{L}^{-1}$ alum). The required alum dose for a desirable $90 \%$ coag_DOC_R would be 96.9 $\mathrm{mg} \mathrm{L}^{-1}$ alum estimated using Equation 5 $\left(\right.$ alum_p $=-\ln \left(1-\frac{90}{100}\right) \times 42.1=$ $\left.96.9 \mathrm{mg} \mathrm{L}^{-1}\right)$.

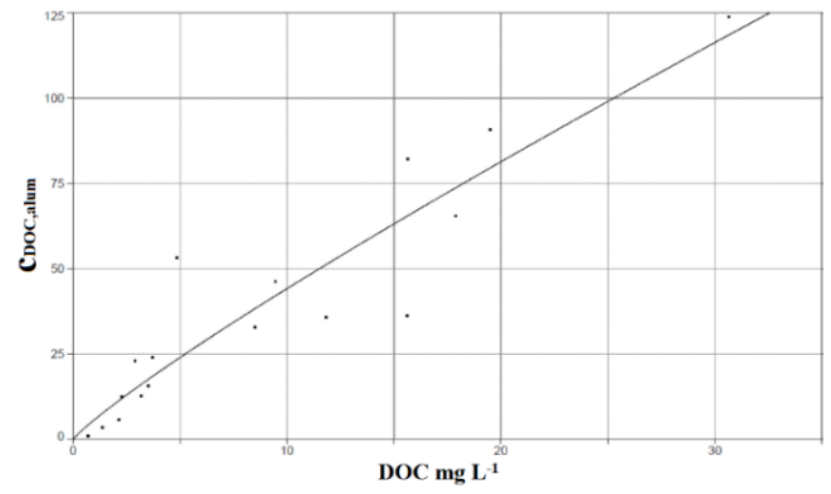

Figure 2. Fitting $C_{D O C}$, alum versus DOC in 17 different water samples; $\left(f_{\text {DOC,alum }}=5.8 \mathrm{mg} \mathrm{L}^{-1}\right.$ alum; $g_{\text {DOC,alum }}=0.88$; Adjusted $R^{2}=0.84$ 
What \%coag_DOC_R should be applied for coagulant dosing at a particular DWTP? Since the EnD concept has been established as a standard for coagulation to optimise DOC removal and for DBP control, we tried to translate this concept into a $\%$ coag_DOC_R for the surface waters studie $\bar{d}$. This is similar to the US EPA standard (Safe Drinking Water Act) for water authorities in the USA to remove prescribed amounts of organic matter (as TOC) based on raw water TOC concentration and alkalinity. The $\%$ coag_DOC_R value could be selected to address different organic matter characters and consequently, variance in coagulability. van Leeuwen et al. (2003) applied a rate of $0.015 \mathrm{mg}$ DOC removal per $\mathrm{mg}$ alum addition as a setpoint for surface waters then tested in Australia. This setpoint is to address

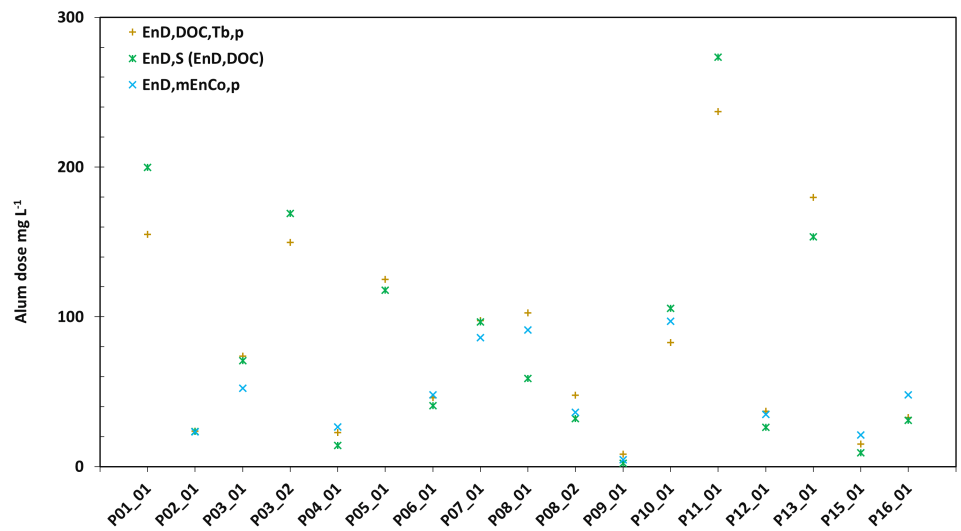

Figure 3. The comparison between EnD obtained through the new DOC model $\left(\mathrm{EnD}_{\mathrm{DOC}, \mathrm{Tb}, \mathrm{p}}\right)$ with EnD obtained either experimentally and through jar test data $\left(\mathrm{EnD}_{\mathrm{DOC}}\right.$ or $\left.\mathrm{EnD}_{\mathrm{s}}\right)$ or the $\mathrm{EnD}$ obtained through the mEnCo software using colour, $\mathrm{A}_{254}$, and turbidity data $\left(\mathrm{EnD}_{\mathrm{mEnCo}, \mathrm{p}}\right)^{1}$ the characteristics of organic matter discharged from various catchments into local surface water sources.

The translation procedure using first derivative analysis of the fitted models was conducted for the 17 water samples that were jar tested in this study and the results are shown in Table 1 . The average of the \%coag_DOC removals for these samples is $85.1 \pm 7.9$ (mean $\pm \mathrm{SD}$ ), considered as equivalent to the $0.015 \mathrm{mg}$ DOC per $\mathrm{mg}$ alum removal rate for surface waters. However, a specific percentage value may be more appropriate for source waters based on catchment characteristics and particular surface water quality.

The $85.1 \%$ value was then employed to predict the $\mathrm{EnD}_{\mathrm{s}}\left(\mathrm{EnD}_{\mathrm{DOC}, \mathrm{p}}\right)$ using the raw water DOC value. The required dose for turbidity was separately calculated using the previously developed model by van Leeuwen et al (Van Leeuwen et al., 2003) and added to the $\mathrm{EnD}_{\mathrm{DOC}, \mathrm{p}}$ to provide the required alum dose to remove both DOC and turbidity (i.e., $\left.\mathrm{EnD}_{\mathrm{DOC}, \mathrm{Tb}, \mathrm{p}}\right)$. The results for the water samples that were jar tested are presented in Figure 3. The predicted EnD values $\left(\mathrm{EnD}_{\mathrm{DOC}, \mathrm{Tb}, \mathrm{p}}\right)$ were compared to the EnD obtained experimentally through jar testing $\left(\mathrm{EnD}_{\mathrm{DOC}}\right.$ or $\left.\mathrm{EnD}_{\mathrm{s}}\right)$ and the $\mathrm{EnD}$ obtained through the mEnCo software using colour, $\mathrm{A}_{254}$, and turbidity data $\left(\mathrm{EnD}_{\mathrm{mEnCo}, \mathrm{p}}\right)$. Since the mEnCo software operation limits to the samples with DOC concentration below $14 \mathrm{mg} \mathrm{L}^{-1}$ and $A_{254}$ less than $0.55 \mathrm{~cm}^{-1}$, only the samples in the operational range were used for this comparison. The results presented in Figure 3 show a comparable prediction performance (with

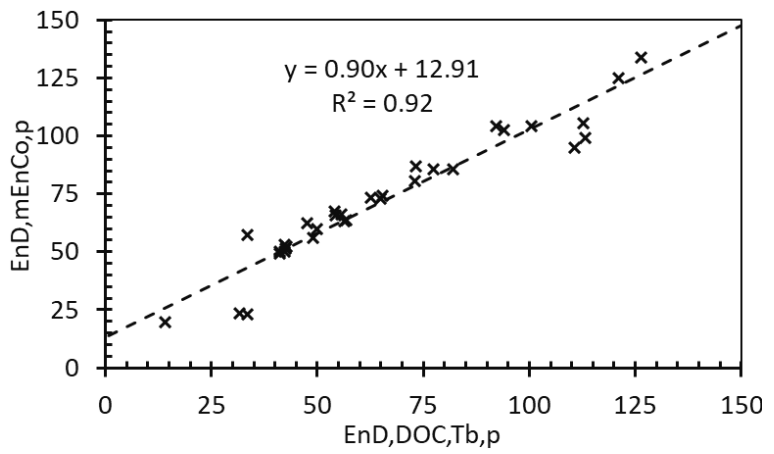

Figure 4. The comparison between EnD obtained through the new DOC model $\left(\mathrm{EnD}_{\mathrm{DOC}, \mathrm{Tb}, \mathrm{p}}\right)$ with $\mathrm{EnD}$ obtained through the mEnCo software using colour, $\mathrm{A}_{254}$, and turbidity data $\left(\mathrm{EnD}_{\mathrm{mEnCo}, \mathrm{p}}\right)^{1}$. a mean of $1 \pm 10 \mathrm{mg} \mathrm{L}^{-1}$ improvement) for comparison between the new developed DOC model and the mEnCo software which requires different input parameter data/signals. The new DOC model shows the practical capability to predict $\mathrm{EnD}_{\mathrm{s}}$ in the samples with higher organic matter content than the operational limits of the mEnCo software. The relative errors $(\%)$ for the five samples were $14.1 \pm 6.1$ (mean $\pm \mathrm{SD})$. These samples are from catchments that had experienced extreme climate conditions of bushfires and cyclones (i.e., P01_01, P03_02, P05_01, P11_01, and P13_01).

Further testing of the DOC model was performed using water samples from nine sources (P01, P02, P03, P04, P05, P08, P11, P13, and P14) where samples had not been employed for the model development (jar test) stage. A comparison was then made between the $\mathrm{EnD}_{\mathrm{DOC}, \mathrm{Tb}, \mathrm{p}}$ and the $\mathrm{EnD}_{\mathrm{mEnCo,p}}$. Since the jar test was not conducted

${ }^{1}$ The comparison performed only for the samples in the operational range of the mEnCo software model 
for these 33 samples, the $\mathrm{EnD}_{\mathrm{s}}$ was not available for further comparison. The high correlation between the new proposed model and the mEnCo predictions (Figure 4) indicates a comparative performance of the two models using the different input signals.

\section{CONCLUSION}

The proposed DOC-based model for alum dose prediction was developed to include a wide range of DOC concentrations of surface waters, used for drinking water supply in Australia, as well as waters impacted by extreme climate events. The proposed model was developed with the intention to be able to be implemented as part of an online control system for DWTPs equipped with online TOC analysers. The developed model is an alternative option to the WTC-Coag software entitled 'WTC-DOC_Coag' using a different input signal which can be used as a complementary option along with previous models to enhance resilience and reliability. Future work will focus on DWTP applicability testing. The developed model might also be used to develop other models based on DOC surrogate parameters such as the UV absorbance of dissolved organic matter present in waters (e.g., $\mathrm{A}_{254}$ ) or fluorescent dissolved organic matter signals with the potential capability to be employed for real-time data acquisition and input for online coagulant dosing control.

\section{ACKNOWLEDGMENTS}

This research was funded by the Australian Government through the Australian Research Council (ARC LP160100217); The authors gratefully thank Mr Adam Leavesley (Bushfire Research Utilisation Manager of the ACT Parks and Conservation Service) and Mr Mark Agnew (Water Officer of the Natural Resources Kangaroo Island) for their so kind contribution to this study by providing several water samples. We also thank all project partners (i.e., Xylem Analytics Australia, SEQ Water, Melbourne Water) for their contributions.

\section{REFERENCES}

Ellis, G.W., Collins, A.G., Ge, X., Ford, C.R., 1991. Chemical dosing of small water utilities using regression analysis. Journal of environmental engineering 117(3) 308-319.

Kastl, G., Sathasivan, A., Fisher, I., Van Leeuwen, J., 2004. Modeling DOC Removal Enhanced Coagulation. Journal-American Water Works Association 96(2) 79-89.

Kennedy, M.J., Gandomi, A.H., Miller, C.M., 2015. Coagulation modeling using artificial neural networks to predict both turbidity and DOM-PARAFAC component removal. Journal of Environmental Chemical Engineering 3(4) 2829-2838.

Knight, N., Shaw, G., Sadler, R., Wickramasinghe, W., 2010. Disinfection by-product formation and minimisation in South East Queensland drinking water. Urban Water Security Research Alliance Technical Report 2344

Pernitsky, D.J., Edzwald, J.K., 2006. Selection of alum and polyaluminum coagulants: principles and applications. Journal of Water Supply: Research and Technology-AQUA 55(2) 121-141.

Szlyk, P.C., Sils, I.V., Francesconi, R.P., Hubbard, R.W., Armstrong, L.E., 1989. Effects of water temperature and flavoring on voluntary dehydration in men. Physiology \& behavior 45(3) 639-647.

Van Leeuwen, J., Chow, C., Bursill, D., Drikas, M., 1999. Empirical mathematical models and artificial neural networks for the determination of alum doses for treatment of southern Australian surface waters. Journal of Water Supply: Research and Technology-AQUA 48(3) 115-127.

Van Leeuwen, J., Daly, R., Holmes, M., 2005. Modeling the treatment of drinking water to maximize dissolved organic matter removal and minimize disinfection by-product formation. Desalination 176(1-3) 81-89.

Van Leeuwen, J., Holmes, M., Heidenreich, C., Daly, R., Fisher, I., Kastl, G., Sathasivan, A., Bursill, D., 2003. Modelling the application of inorganic coagulants and $\mathrm{pH}$ control reagents for removal of organic matter from drinking waters, Proc. Modsim. Citeseer, pp. 1835-1840.

Xie, J., Wang, D., van Leeuwen, J., Zhao, Y., Xing, L., Chow, C.W., 2012. pH modeling for maximum dissolved organic matter removal by enhanced coagulation. Journal of Environmental Sciences 24(2) 276283.

Zhao, Z., Sun, W., Ray, M.B., Ray, A.K., Huang, T., Chen, J., 2019. Optimization and modeling of coagulationflocculation to remove algae and organic matter from surface water by response surface methodology. Frontiers of Environmental Science \& Engineering 13(5) 1-13. 